\title{
Kinetic Framework for Ligation by an Efficient RNA Ligase Ribozyme ${ }^{\dagger}$
}

\author{
Nicholas H. Bergman, Wendy K. Johnston, and David P. Bartel* \\ Whitehead Institute for Biomedical Research and Department of Biology, MIT, 9 Cambridge Center, \\ Cambridge, Massachusetts 02142
}

Received November 17, 1999; Revised Manuscript Received January 10, 2000

\begin{abstract}
The class I RNA ligase ribozyme, isolated previously from random sequences, performs an efficient RNA ligation reaction. It ligates two substrate RNAs, promoting the attack of the $3^{\prime}$-hydroxyl of one substrate upon the 5'-triphosphate of the other substrate with release of pyrophosphate. This ligation reaction has similarities to the reaction catalyzed by RNA polymerases. Using data from steady-state kinetic measurements and pulse-chase/pH-jump experiments, we have constructed minimal kinetic frameworks for two versions of the class I ligase, named 207t and 210t. For both ligases, as well as for the self-ligating parent ribozyme, the rate constant for the chemical step $\left(k_{\mathrm{c}}\right)$ is log-linear with $\mathrm{pH}$ in the range 5.7-8.0. At physiological $\mathrm{pH}$, the $k_{\mathrm{c}}$ is $100 \mathrm{~min}^{-1}$, a value similar to those reported for the fastest naturally occurring ribozymes. At higher $\mathrm{pH}$, product release is limiting for both $207 \mathrm{t}$ and $210 \mathrm{t}$. The $210 \mathrm{t}$ ribozyme, with its faster product release, attains multiple-turnover rates $\left(k_{\mathrm{cat}}=360 \mathrm{~min}^{-1}, \mathrm{pH} 9.0\right)$ exceeding those of $207 \mathrm{t}$ and other reported ribozyme reactions. The kinetic framework for the $210 \mathrm{t}$ ribozyme describes the limits of this catalysis and suggests how key steps can be targeted for improvement using design or combinatorial approaches.
\end{abstract}

RNA ligase ribozymes were previously isolated from a large pool of random sequences based on their ability to join a substrate oligonucleotide to their own $5^{\prime}$ terminus (1). These new ribozymes promote attack by a terminal hydroxyl of the substrate RNA upon the $\alpha$-phosphate of the ribozyme triphosphate, joining the two RNAs, with release of pyrophosphate (eq 1 , where $\mathrm{S}^{\mathrm{OH} 1}$ is the substrate oligo, ${ }^{\mathrm{PPP}} \mathrm{R}$ is

$$
\mathrm{S}^{\mathrm{OH}}+{ }^{\mathrm{PPP}} \mathrm{R} \rightarrow \mathrm{P}+\mathrm{PP}_{\mathrm{i}}
$$

the ribozyme, $\mathrm{P}$ is the ligation product, and $\mathrm{PP}_{\mathrm{i}}$ is inorganic pyrophosphate). Seven of these ligases have been examined and grouped into three classes based on secondary structure and ligation regiospecificity (2).

Of the three classes, the class I ligase (Figure 1A) has been the most extensively studied. This ribozyme promotes a reaction analogous in three respects to a single step of templated RNA polymerization: an RNA 3'-hydroxyl attacks the $\alpha$-phosphate of a $5^{\prime}$-triphosphate, a new phosphodiester bond is formed with concomitant displacement of pyrophosphate, and the molecules that are joined are aligned by Watson-Crick pairing (Figure 1A). Indeed, variants of the class I ligase have been designed that use an RNA template and nucleoside triphosphates to extend an RNA primer by

\footnotetext{
This work was supported by a grant from the NIH.

* To whom correspondence should be addressed. Fax: (617) 2586768. E-mail: dbartel@wi.mit.edu.

${ }^{1}$ Abbreviations: $\mathrm{PP}_{\mathrm{i}}$, inorganic pyrophosphate; $\mathrm{S}^{\mathrm{OH}}$, smaller of two substrates (5'-aaaCCAGUC, DNA bases lowercase); ${ }^{\text {PPP }}$, larger substrate (5'-pppGGAACACUAUACGACUGGCACCA or pppGGAACGAAAUACGACUGGCACCA); EDTA, ethylenediaminetetraacetic acid; MES, 2-[N-morpholino]ethanesulfonic acid; BES, $N, N$-bis[2hydroxyethyl]-2-aminoethanesulfonic acid; EPPS, $N$-[2-hydroxyethyl]piperazine- $N^{\prime}$-[3-propanesulfonic acid]; CHES, 2-[ $N$-cyclohexylamino]ethanesulfonic acid; RNase P, Ribonuclease P.
}
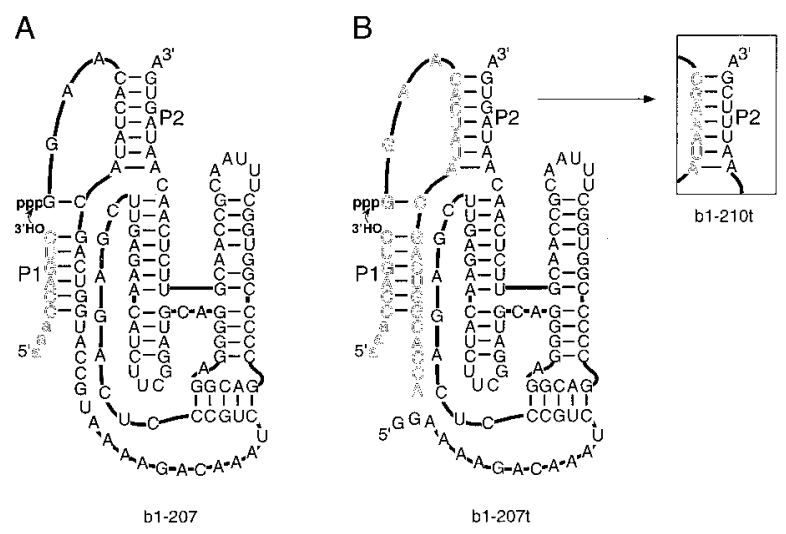

FiguRE 1: Class I ligase. (A) The class I ligase promotes the attack of the 3'-OH of the substrate RNA ( $\mathrm{S}^{\mathrm{OH}}$, outline typeface) on its own $5^{\prime}-\alpha$-phosphate, creating a new $3^{\prime}-5^{\prime}$ linkage with concomitant release of pyrophosphate. P1 and P2 indicate the first two paired regions of the ribozyme-substrate complex; lowercase type indicates DNA. (B) Multiple-turnover derivatives ligate a bimolecular substrate complex ( $\mathrm{S}^{\mathrm{OH} \cdot \mathrm{PPP}} \mathrm{S}$, outline typeface). The 210t ribozyme was engineered by changing the arrangement of the base pairs in the P2 stem as shown (box).

three to six nucleotides (3). The ability of class I variants to synthesize RNA using the same reaction that is employed by biological polymerases supports the idea of RNA selfreplication during the early evolution of life $(3,4)$.

The reaction promoted by the class I ligase is also uniquely suited for continuous in vitro evolution experiments. During continuous evolution, ribozymes are propagated based on their ability to ligate themselves to a substrate RNA before they are inactivated by becoming a template for cDNA synthesis (5). Because selection can be maintained by simple serial transfer, the approach allows rapid and convenient sequence reoptimization following modification of selection 
criteria by, for example, changes to reaction conditions or the nature of the substrate (5). This process is also an attractive in vitro simulation of natural evolution, which may provide insight into the evolution of biocatalysts.

The class I ligase is remarkably large for a ribozyme that emerged from random sequences. The secondary structure of the class I ligase complexed with its substrate RNA is a nested double pseudoknot with seven stems and two critical extended joining regions [Figure 1A (6)]. Finding such a large and complex ligase in a limited sampling of sequence space suggests the existence of a very large number of distinct structures of equivalent complexity and activity (2).

Perhaps as a consequence of its large size, it has been possible to use a combination of in vitro evolution and engineering approaches to generate variants of the original class I isolate (isolate b1) that are very efficient in the selfligation reaction $(6)$. The self-ligation rate of one of these variants (construct b1-207, Figure 1A) is too fast to measure accurately by manual pipetting, with the reaction mostly completed within the first $5 \mathrm{~s}$ (2). Nevertheless, ligation rates are easily measured in a multiple-turnover context, where a complex of the two RNA substrates to be ligated is separated from the core of the ribozyme (Figure 1B, eq 2 ), allowing

$$
\mathrm{S} \stackrel{\mathrm{OH} \cdot \mathrm{PPP}}{\mathrm{S}} \stackrel{\stackrel{E}{\rightarrow}}{\mathrm{P}}+\mathrm{PP}_{\mathrm{i}}
$$

each ribozyme to ligate many molecules prior to the first time point. With the multiple-turnover format, a version of the ligase (variant b1-210t; Figure 1B) has a $k_{\text {cat }}$ exceeding $1 \mathrm{~s}^{-1}-\mathrm{a}$ value greater than those of other ribozymes and approaching those of comparable protein enzymes (2).

To understand the basis for this unusually high catalytic rate, as well as the current limits of this rate, we have constructed a minimal kinetic framework for the ligation reaction. Identifying the rate-limiting steps of the reaction and understanding the factors that change them provides a basis for comparing the ligase with other characterized ribozymes and for comparing the prototype ligase construct with new variants that emerge from continuous evolution or other selection experiments. These results also suggest strategies for further improving catalytic rates and form a foundation for future mechanistic studies of RNA-catalyzed RNA ligation and polymerization.

\section{MATERIALS AND METHODS}

Substrate RNAs and Ribozymes. The smaller of the two substrates $\left(\mathrm{S}^{\mathrm{OH}}\right)$ was an RNA-DNA hybrid [5'-aaCCAGUC, DNA bases lowercase (6)]. It was synthesized by standard phosphoramidite chemistry (7) and purified by anionexchange chromatography (Nucleopac $9 \times 250$ column, Dionex). The larger substrates ( $\left.{ }^{\mathrm{PPP}} \mathrm{S}\right)$ for the multiple-turnover derivatives (5'-pppGGAACACUAUACGACUGGCACCA and pppGGAACGAAAUACGACUGGCACCA; Figure 1) were made by in vitro transcription of synthetic DNA by T7 RNA polymerase (8). Transcripts were purified on $15 \%$ polyacrylamide/ $8 \mathrm{M}$ urea gels, taking care to exclude longer transcripts with one or more untemplated residues. The selfligating ribozyme (b1-207, Figure 1a; Genbank no. U26413) was transcribed in vitro from a plasmid template linearized with EarI. Both multiple-turnover derivatives (Figure 1b) were transcribed from PCR-amplified DNA that was gener- ated using the b1-207 plasmid and primers that produce the desired base changes and truncations. Ribozymes were purified on $6 \%$ or $8 \%$ acrylamide/ $8 \mathrm{M}$ urea gels. RNA concentration was determined spectrophotometrically at 260 $\mathrm{nm}$, assuming an extinction coefficient that was the sum of those for the individual nucleotides (9).

Radiolabeling of RNAs. $\mathrm{S}^{\mathrm{OH}}$ was labeled using T4 poly-

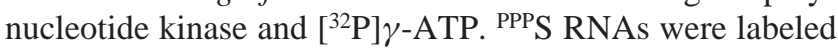
using $\left[{ }^{32} \mathrm{P}\right] \alpha$-cordycepin triphosphate and yeast poly $(\mathrm{A})$ polymerase (United States Biochemical) to add a radiolabeled 3'-deoxyadenosine nucleotide to a 22-nt version of each substrate which lacked the $3^{\prime}$-terminal A. Ribozymes were body labeled by including $\left[{ }^{32} \mathrm{P}\right] \alpha$-UTP in the transcription.

Kinetic Assays and Measurement of Michaelis-Menten Parameters. All ribozyme reactions were performed in 50 $\mathrm{mM}$ buffer, $60 \mathrm{mM} \mathrm{MgCl} 2,200 \mathrm{mM} \mathrm{KCl}$, and $600 \mu \mathrm{M}$ EDTA at $22{ }^{\circ} \mathrm{C}$. Buffers were MES (pH 5.7, 6.0, 6.5), BES (pH 6.7, 7.0, 7.4), EPPS (pH 8.0, 8.5), or CHES (9.0, 9.5). In all cases, the ribozyme was heated $\left(2 \mathrm{~min}\right.$ at $80{ }^{\circ} \mathrm{C}$ in $\left.\mathrm{H}_{2} \mathrm{O}\right)$ and then cooled $\left(2 \mathrm{~min}\right.$ at $22^{\circ} \mathrm{C}$ ) just prior to initiation

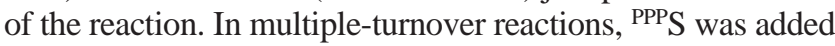
to the ribozyme RNA before heating. Both self-ligation and multiple-turnover ligation reactions were initiated by simultaneous addition of buffer, salts, and $\mathrm{S}^{\mathrm{OH}}$ to the ribozyme solution. Aliquots were taken at specified time points and added to 2 vol of a stop solution (8 M urea, $100 \mathrm{mM}$ EDTA). Product and substrate were separated on $20 \%$ (reactions with labeled $\mathrm{S}^{\mathrm{OH}}$ ) or $15 \%$ (reactions with labeled ${ }^{\mathrm{PPP}} \mathrm{S}$ ) polyacrylamide gels, then quantified by phosphorimaging (Fuji BAS 2000).

In most single-turnover experiments $\mathrm{S}^{\mathrm{OH}}$ was radiolabeled and used in trace quantities $(<100 \mathrm{nM})$ with saturating amounts (usually $1 \mu \mathrm{M}$ ) of ribozyme. (Pilot experiments showed that $1 \mathrm{nM}$ labeled $\mathrm{S}^{\mathrm{OH}}$ was half-saturated at $40 \mathrm{nM}$ ribozyme.) More than $99 \%$ of $\mathrm{S}^{\mathrm{OH}}$ was capable of being ligated. Rates of single-turnover reactions were calculated from eq 3,

$$
\text { Fraction reacted }=F_{\mathrm{a}}\left(1-\mathrm{e}^{-k t}\right)
$$

where $t$ equals time, $k$ equals the rate of catalysis, and $F_{\text {a }}$ equals the fraction of substrate that reacts in an initial burst. The $F_{\text {a }}$ (typically 0.7 ) was interpreted to represent the fraction of substrate ribozyme in an active conformation. Experiments measuring the fraction of enzyme capable of reacting were performed similarly, except that the ribozyme $(1 \mu \mathrm{M})$ was labeled and incubated with saturating unlabeled substrate (10 $\mu \mathrm{M})$.

For standard multiple-turnover experiments, ${ }^{\mathrm{PPP}} \mathrm{S}$ was radiolabeled and used with sufficient unlabeled $\mathrm{S}^{\mathrm{OH}}$ to ensure that nearly all the PPPS was complexed. Control experiments showed that a $25 \mu \mathrm{M}$ excess of $\mathrm{S}^{\mathrm{OH}}$ did not affect reaction rates. (This use of radiolabeled ${ }^{\mathrm{PPP}} \mathrm{S}$ with saturating $\mathrm{S}^{\mathrm{OH}}$ allowed accurate examination of low concentrations of $\mathrm{S}^{\mathrm{OH} \cdot \mathrm{PPP}} \mathrm{S}$ complex. Reactions with high $\mathrm{S}^{\mathrm{OH} \cdot \mathrm{PPP}} \mathrm{S}$ concentrations could also be performed using labeled $\mathrm{S}^{\mathrm{OH}}$ and equimolar ${ }^{\mathrm{PPP}} \mathrm{S}$; in this study, the only multiple-turnover reactions in which $\mathrm{S}^{\mathrm{OH}}$ was labeled were the reactions of $210 t$ reported in Figure 3, where both substrates were at 35 $\mu \mathrm{M})$. Extended time courses showed that $85-90 \%$ of the ${ }^{\mathrm{PPP} S}$ was capable of reacting to form product. Rates of 
multiple-turnover reactions were measured as initial rates $(<20 \%$ of the substrate converted to product). Values for $k_{\text {cat }}$ and $K_{\mathrm{m}}$ were determined by measuring the reaction rate at least twice at each of at least four ${ }^{\text {PPPS }}$ concentrations, then fitting the data to the Michaelis-Menten equation using a nonlinear, least squares algorithm (DeltaGraph 3.5, Deltapoint).

Preparation of Ligated Product and Determination of $K_{i}$ for Each Product-Ribozyme Complex. Standard ribozyme reactions were scaled up to generate ligated product for b1$207 t$ and b1-210t. Products were gel purified and added to the ribozyme reactions with ${ }^{\mathrm{PPP} S}$, prior to the $80{ }^{\circ} \mathrm{C}$ incubation. The $K_{\mathrm{i}}$ for each was determined from the best fit to eq 4 .

$$
k_{\mathrm{obs}}=\frac{[\mathrm{S}] k_{\mathrm{cat}}}{[\mathrm{S}]+\left(K_{\mathrm{m}}\left(1+\frac{[\mathrm{I}]}{K_{\mathrm{i}}}\right)\right)}
$$

pH-Jump Partitioning Experiments. Ribozyme $(1 \mu \mathrm{M})$ and labeled $S^{\mathrm{OH} \cdot \mathrm{PPP}} \mathrm{S}$ complex were mixed in reaction buffer at $\mathrm{pH}$ 6.0. The low $\mathrm{pH}$ slowed catalysis such that only $24 \%$ of the $\mathrm{S}^{\mathrm{OH} \cdot \mathrm{PPP} S}$ reacted in the first $10 \mathrm{~s} .{ }^{\mathrm{PPP} S}$ was radiolabeled and included at trace concentration $(<25 \mathrm{nM})$, and $\mathrm{S}^{\mathrm{OH}}$ was kept at $25 \mu \mathrm{M}$, well above saturating concentration. At these concentrations, the majority of the $\mathrm{S}^{\mathrm{OH} \cdot \mathrm{PPP}} \mathrm{S}$ complex is bound, and substrate dissociation rates reflect the dissociation of the $\mathrm{S}^{\mathrm{OH} \cdot \mathrm{PPP}} \mathrm{S}$ complex from the ribozyme. After $10 \mathrm{~s}$ at $22{ }^{\circ} \mathrm{C}$, the reaction was mixed with an equal volume of a solution that increased the $\mathrm{pH}$ to the desired value (6.08.0). Each experiment was done with and without a substrate chase that added unlabeled $S^{\mathrm{OH} \cdot \mathrm{PPP}} \mathrm{S}$ complex to a final concentration of $20 \mu \mathrm{M}$. Parallel experiments were done for each $\mathrm{pH}$ in which the unlabeled $\mathrm{S}^{\mathrm{OH} \cdot \mathrm{PPP}} \mathrm{S}$ complex was mixed with the labeled $S^{\mathrm{OH} \cdot \mathrm{PPP}} \mathrm{S}$ complex before starting the reaction.

Computer Simulation of pH-jump Partitioning Experiments. Data obtained from the partitioning experiments were compared to simulated experiments done using the program KINSIM (10). Reactions were simulated using eqs 5-10,

$$
\begin{gathered}
\mathrm{E}+\mathrm{S} \Leftrightarrow \mathrm{ES} \Leftrightarrow \mathrm{EP} \Leftrightarrow \mathrm{E}+\mathrm{P} \\
\mathrm{E}+\mathrm{I} \Leftrightarrow \mathrm{EI} \Leftrightarrow \mathrm{ER} \Leftrightarrow \mathrm{E}+\mathrm{R} \\
\mathrm{F}+\mathrm{S} \Leftrightarrow \mathrm{FS} \\
\mathrm{F}+\mathrm{P} \Leftrightarrow \mathrm{FP} \\
\mathrm{F}+\mathrm{I} \Leftrightarrow \mathrm{FI} \\
\mathrm{F}+\mathrm{R} \Leftrightarrow \mathrm{FR}
\end{gathered}
$$

where $\mathrm{E}=$ enzyme, $\mathrm{S}=$ labeled substrate, $\mathrm{P}=$ labeled product, $\mathrm{I}=$ inactive substrate and unlabeled chase substrate, $\mathrm{R}=$ unlabeled product, and $\mathrm{F}=$ inactive enzyme.

Equation 5 is essentially the mechanism shown in Scheme 1 (neglecting pyrophosphate release, which is very fast), and eqs $6-10$ duplicate the mechanism so that inactive and active versions of both ribozyme and substrate can be considered independently. The rate constants presented in Scheme 1 are those that fit the data using the simplest model, wherein the reverse reaction is negligible and binding of substrate and product is unaffected by whether the ribozyme is active (E) or inactive $(\mathrm{F})$.

Simulations of partitioning experiments were done by calculating the concentrations of all reactant species after $10 \mathrm{~s}$ at $\mathrm{pH} 6.0$ with $1 \mu \mathrm{M} \mathrm{E}$ and $25 \mathrm{nM} \mathrm{S}$ and using these values as the starting point for a new simulation reflecting the changed concentrations, volume, and $\mathrm{pH}$ at the beginning of the partitioning.

Note that the interconversions described by eqs $11-15$

$$
\begin{gathered}
\mathrm{E} \Leftrightarrow \mathrm{F} \\
\mathrm{ES} \Leftrightarrow \mathrm{FS} \\
\mathrm{EP} \Leftrightarrow \mathrm{FP} \\
\mathrm{EI} \Leftrightarrow \mathrm{FI} \\
\mathrm{ER} \Leftrightarrow \mathrm{FR}
\end{gathered}
$$

are absent from our model.

This simplification is justified if there are no significant changes in the equilibrium between active and inactive enzyme conformations upon binding substrate or if the interconversions are slow relative to the duration of the experiment. The slow reaction rate observed for the second phase of the self-ligation reaction suggests that the interconversion does in fact take much longer (30-60 min) than the longest partitioning experiments reported here $(2 \mathrm{~min})$.

\section{RESULTS}

Chemical Step $\left(k_{c}\right)$ Is Rate-Limiting at Low pH. As with many protein-catalyzed reactions, ribozyme reactions are often limited by product dissociation or conformational changes rather than by $k_{\mathrm{c}}$, the rate constant for the chemical transformation $(11-16)$. For ribozyme reactions involving phosphoryl transfer, the attacking hydroxyl typically needs to be deprotonated during $k_{\mathrm{c}}$. Therefore, examining the influence of $\mathrm{pH}$ on $k_{\mathrm{cat}}$ is useful for investigating whether $k_{\mathrm{c}}$, the step involving chemical transformation, might be rate limiting $(12,15,17-20)$.

The influence of $\mathrm{pH}$ on reaction rate was tested using the single-turnover version of the class I ligase. The analysis of these data was complicated by the fact that the ribozymes in a given preparation had nonuniform activity. Experiments using radiolabeled ribozyme and unlabeled substrate showed that there were three populations of self-ligase ribozymes (unpublished data). At $\mathrm{pH}$ 8.0, the major fraction (70\%) reacted within a 5-s burst. A minor fraction (15\%) was inactive, which can be explained at least in part by loss of the $5^{\prime}$-triphosphate during transcription. The remaining fraction (15\%) reacted, but at a slow rate, reaching a plateau only after $30-60 \mathrm{~min}$. We suggest that this very slowreacting fraction is trapped in an inactive conformation, and the additional time needed reflects the slow interconversion between inactive and active conformations. Although this fraction does eventually form product, its reaction rate is sufficiently slow to be grouped with the inactive fraction; all rates reported in this study reflect those of the fast-reacting fraction.

At $\mathrm{pH} \leq 7.0$, self-ligation rates were slow enough to be measured accurately by manual pipetting (Figure 2). In the $\mathrm{pH}$ range 5.7-7.0, self-ligation activity was log-linear with 


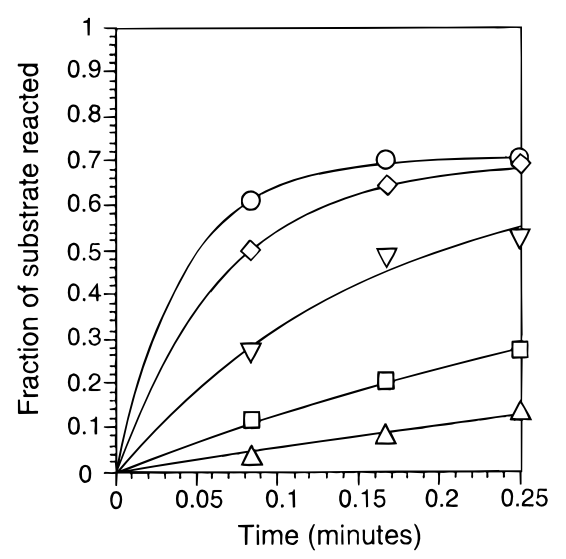

Figure 2: Class I self-ligation. Representative time courses are shown for self-ligation of the 207 construct at pH $5.7(\triangle), 6.0(\square)$, $6.5(\nabla), 7.0(\diamond)$, and $8.0(\bigcirc)$. Radiolabeled substrate $(<100 \mathrm{nM})$ was incubated in reaction buffer with $1 \mu \mathrm{M}$ unlabeled ribozyme. Each curve indicates the nonlinear, least-squares best fit to eq 3 using an $F_{\text {a }}$ of 0.7 .

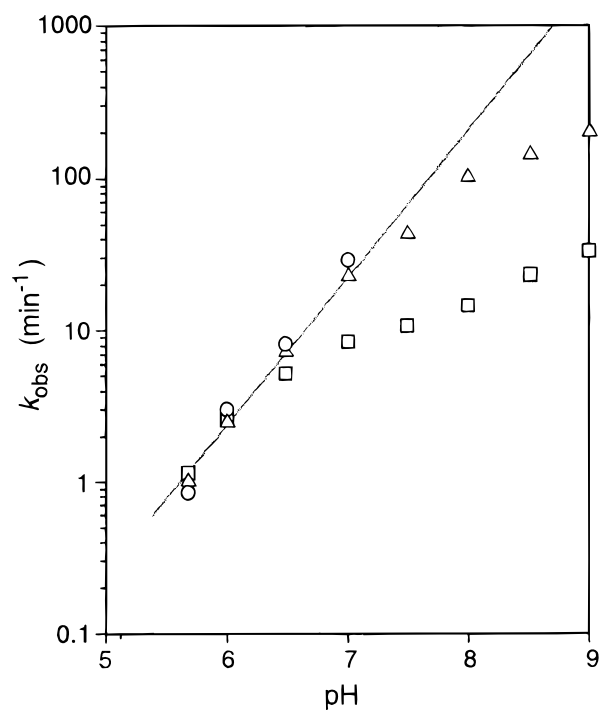

Figure 3: The $\mathrm{pH}$ dependence of ligation. The rates shown are those of $207(\bigcirc), 207 \mathrm{t}(\square)$, and $210 \mathrm{t}(\triangle)$. The 207 rate constants are for single-turnover, self-ligation reactions, as shown in Figure 2. Multiple-turnover rates under steady-state conditions were measured for $207 \mathrm{t}$ using $10 \mu \mathrm{M}$ radiolabeled ${ }^{\mathrm{PPP}} \mathrm{S}, 12 \mu \mathrm{M} \mathrm{S} \mathrm{SH}^{\mathrm{O}}$, and $25 \mathrm{nM}$ enzyme. Multiple-turnover rates for $210 \mathrm{t}$ were measured using $35 \mu \mathrm{M}{ }^{\mathrm{PPP}} \mathrm{S}, 35 \mu \mathrm{M}$ radiolabeled $\mathrm{S}^{\mathrm{OH}}$, and $25 \mathrm{nM}$ enzyme. Each rate is the average of at least two independent measurements. $k_{\text {obs }}$ approximates $k_{\text {cat }}$ in most cases, except for $210 \mathrm{t}$ above $\mathrm{pH} 7$, where the increasing $K_{\mathrm{m}}$ made saturating concentrations of substrate difficult to attain. The line is log-linear with a slope of 1.0. Control experiments showed that at representative $\mathrm{pH}$ values the identity and concentration of the buffer did not noticeably influence observed rates (data not shown).

$\mathrm{pH}$, slope $=1.0$ (Figure 3, circles). The direct correspondence between the hydroxide ion concentration and the reaction rate indicated that a single deprotonation is rate limiting and suggested a rate-limiting $k_{\mathrm{c}}$ at low $\mathrm{pH}$.

The effects of $\mathrm{pH}$ on the reaction rate of two multipleturnover derivatives, 207t and 210t (Figure 1B), were also examined. Both substrates were at concentrations of $>20$ $\mu \mathrm{M}$, well above the $K_{\mathrm{d}}$ of the $\mathrm{P} 1$ helix, allowing the substrate pairs ( $\mathrm{S}^{\mathrm{OH}}$ and $\left.{ }^{\mathrm{PPP}} \mathrm{S}\right)$ to be treated as a unimolecular substrate complex ( $\mathrm{S}^{\mathrm{OH} \cdot \mathrm{PPP}} \mathrm{S}$ in eq 2). As with self-ligation, multipleturnover ligation at $\mathrm{pH}<7.0$ was log-linear with $\mathrm{pH}$, slope $=1.0$ (Figure 3 ), again suggesting rate-limiting $k_{\mathrm{c}}$ at low
$\mathrm{pH}$. Indeed, at $\mathrm{pH}<7.0$, the rates of both the $207 \mathrm{t}$ and $210 \mathrm{t}$ reactions closely matched the rate of self-ligation. Thus, the break in the RNA chain engineered to convert self-ligation to multiple-turnover (Figure 1) does not compromise the activity of the ligase.

The suggestion of a rate-limiting $k_{\mathrm{c}}$ at a phosphate diester can be corroborated by observing an elemental effect when one of the nonbridging oxygens is replaced with sulfur (21, 22 ). For the class I ligase, thio effects are most conveniently examined using the primer extension format (3) and the two $\alpha$-thio-GTP diastereomers. In this format, the thio effect matches $\left(S_{\mathrm{P}}\right.$ substitution) or exceeds $\left(R_{\mathrm{P}}\right.$ substitution) the expected elemental effect (M. Glasner, C. Yen, E. Ekland, D. P. B., manuscript in preparation). Thus, given the $\mathrm{pH}$ rate profiles together with this apparent elemental effect for the class I ligase in the primer-extension format, it is reasonable to conclude that $k_{\mathrm{c}}$ is rate-limiting at low $\mathrm{pH}$. As with other ribozymes, the critical deprotonation during the chemical step is most likely that of the attacking hydroxyl of the substrate $(14,15,17,22)$.

Product Release Is Rate-limiting at High $p H$. Above neutral $\mathrm{pH}$, the $207 \mathrm{t}$ construct did not maintain log-linear behavior (Figure 3). The 207t and 210t enzyme-substrate pairs differ only at three base pairs within the P2 helix, the helix that plays a major role in substrate and product binding (Figure 1B). Because the 207t P2 helix is predicted to be somewhat more stable than the 210t helix $\left[\Delta \Delta G_{22^{\circ}}^{\circ}=-1.3\right.$ $\mathrm{kcal} / \mathrm{mol}$ in $1 \mathrm{M} \mathrm{NaCl}(23)]$, the $207 \mathrm{t}$ ribozyme would be expected to have a slower product dissociation rate constant. Therefore, the simplest explanation for the divergence of the $\mathrm{pH}$ profiles for these two constructs is that product dissociation becomes rate limiting as $k_{\mathrm{c}}$ increases. Since the rate constant for product dissociation is expected to be slower for $207 \mathrm{t}$ than for $210 \mathrm{t}$, the break in the $\mathrm{pH}$-rate profile should occur at a lower $\mathrm{pH}$, and the $\mathrm{pH}$-independent rate constant should be slower, as observed.

Varying $\mathrm{pH}$ between 6.0 and 8.0 generally has little influence on RNA structure. The titration of moieties within this range would require a dramatic, though not unprecedented (24) perturbation in $\mathrm{p} K_{\mathrm{a}}$ (nearest $\mathrm{p} K_{\mathrm{a}} \mathrm{s}$ of nucleotides: cytidine $\mathrm{N}_{3}, 4.5$; guanosine $\mathrm{N}_{1}, 10.0$; uridine $\mathrm{N}_{3}, 10.1$; ref 25). Therefore, it would be surprising if the rates of product dissociation or ribozyme conformational transition were influenced by $\mathrm{pH}$ changes within this range so as to confound interpretation of our results. However, it should be noted that the $\gamma$-phosphate of ${ }^{\mathrm{PPP}} \mathrm{S}$ is expected to deprotonate within this range ( $\mathrm{p} K_{\mathrm{a}}$ of the $\gamma$-phosphate of ATP $=6.8$ ). The $\gamma$-phosphate is in the vicinity of the catalytic site, and its deprotonation might influence catalytic rate. A transition in the $\mathrm{pH}$-rate profile for both constructs near $\mathrm{pH}$ 6.8 would have suggested the importance of this deprotonation. However, the 210t profile had no transition in the vicinity of $\mathrm{pH} 6.8$ (Figure 3); if deprotonation of the $\gamma$-phosphate is truly relevant, its $\mathrm{p} K_{\mathrm{a}}$ would have to be perturbed by over 2 units. It is interesting that the 207t rates accelerated again above $\mathrm{pH}$ 8.0. This could be explained by increased product-dissociation rates as multiple moieties involved in product binding began to deprotonate (26).

Steady-State Parameters $\left(k_{\mathrm{cat}}, K_{\mathrm{m}}\right.$, and $\left.K_{\mathrm{i}}\right)$. To better understand the influence of $\mathrm{pH}$ on the multiple-turnover ligation reactions, Michaelis-Menten parameters were determined for the two constructs at two extreme $\mathrm{pHs}, 6.0$ and 


\begin{tabular}{cccccc}
\hline Table 1: & Michaelis-Menten Parameters for Ligase Ribozymes \\
\hline & \multicolumn{2}{c}{ b1-207t } & & \multicolumn{2}{c}{ b1-210t } \\
\cline { 2 - 3 } \cline { 5 - 6 } & $\begin{array}{c}k_{\text {cat }} \\
\left(\mathrm{min}^{-1}\right)\end{array}$ & $\begin{array}{c}K_{\mathrm{m}} \\
(\mu \mathrm{M})\end{array}$ & & $\begin{array}{c}k_{\text {cat }} \\
\left(\mathrm{min}^{-1}\right)\end{array}$ & $\begin{array}{c}K_{\mathrm{m}} \\
(\mu \mathrm{M})\end{array}$ \\
\hline pH 6.0 & 3 & 0.22 & & 3 & 4.2 \\
pH 8.0 & 16 & 0.23 & & 140 & 7.8 \\
pH 9.0 & 35 & 1.5 & & 360 & 25 \\
\hline
\end{tabular}

9.0, as well as at $\mathrm{pH} \mathrm{8.0,} \mathrm{the} \mathrm{pH}$ of the inflection point of the $207 \mathrm{t}$ curve (Table 1 ). At low $\mathrm{pH}$, the $k_{\mathrm{cat}} \mathrm{s}$ reflected the rates plotted in Figure 3, as expected, given that the concentration of $\mathrm{S}^{\mathrm{OH} \cdot \mathrm{PPP}} \mathrm{S}$ was at least 10 -fold above the $\mathrm{pH}$ $6 K_{\mathrm{m}}$ s. However, the $K_{\mathrm{m}}$ for both constructs significantly increased with increasing $\mathrm{pH}$, such that the $210 \mathrm{t} K_{\mathrm{m}}$ at $\mathrm{pH} 9$ $(25 \mu \mathrm{M})$ approached the substrate concentration used in Figure $3(35 \mu \mathrm{M})$. Therefore, part of the plateau observed for $210 \mathrm{t}$ rates at high $\mathrm{pH}$ (Figure 3) can be explained by increased substrate concentrations needed for effective ribozyme saturation.

There are several explanations for the remaining deviation of $210 \mathrm{t}$ rates from log-linear behavior. Complete deprotonation of the attacking 3 -hydroxyl would produce this deviation, but this would require a $K_{\mathrm{a}}$ shift of $\sim 3$ units (from 12.4 to $\leq 9.0$ ). Similarly, it is difficult to rule out deprotonation at other sites that interfere with the chemical step (26). Nevertheless, we favor the possibility that, as with the $207 \mathrm{t}$ ribozyme, $k_{\mathrm{c}}$ remains $\mathrm{pH}$ dependent, and the plateau arises from a change to a different rate-limiting step, i.e., product dissociation.

To supplement the Michaelis-Menten constants listed in Table 1 and to more accurately assess product binding, the inhibition constant $\left(K_{\mathrm{i}}\right)$ for the product of each ribozyme was measured. Because in each case the inhibition was competitive, $K_{\mathrm{i}}$ equals the $K_{\mathrm{d}}$ of the product $(0.23 \mu \mathrm{M}$ for $207 \mathrm{t}, 13$ $\mu \mathrm{M}$ for 210t) (Figure 4). Studies of model RNA helices predict that the two product ribozyme helices would differ by $1.3 \mathrm{kcal} / \mathrm{mol}$, corresponding to a 9 -fold difference in affinity (23). The measured difference in product-binding affinities between $210 \mathrm{t}$ and $207 \mathrm{t}$ was 6 -fold more than that expected, and it is intriguing to consider the possibility that, in shuffling the three base pairs that distinguish the two enzyme-substrate complexes (Figure 1B), we disrupted a tertiary contact that favors enzyme -substrate/product binding.

Despite this difference between the two ribozymes, the overall picture of product affinity largely matches that predicted from the simple formation of the P2 helix. The predicted $\Delta G_{22^{\circ}}^{\circ}$ of helix formation is 8.7 and $7.4 \mathrm{kcal} / \mathrm{mol}$ for the $207 \mathrm{t}$ and $210 \mathrm{t}$, respectively [in $1 \mathrm{M} \mathrm{NaCl}$, including $-2.5 \mathrm{kcal} / \mathrm{mol}$ as the contribution of the A:A mismatches at both ends of the helix $(23,27)]$. The $K_{\mathrm{i}}$ s correspond to $\Delta G^{\circ} \mathrm{S}$ of 9.0 and $6.6 \mathrm{kcal} / \mathrm{mol}$ for $207 \mathrm{t}$ and $210 \mathrm{t}$; both are within 1 $\mathrm{kcal} / \mathrm{mol}$ of the predicted values. The P2 helix is somewhat removed from the site of chemistry; for catalysis, there must also be ribozyme contacts to the ligation junction. How could essentially all the product binding be explained by the formation of the $\mathrm{P} 2$ helix? One possibility is that additional contacts that favor substrate/product binding are offset by contacts that destabilize the substrate/product without destabilizing the transition state, a known catalytic strategy of the group I intron (28).

Minimal Kinetic Framework for 207t. The 207t ribozyme reaction was modeled using the steady-state data at $\mathrm{pH} 6.0$
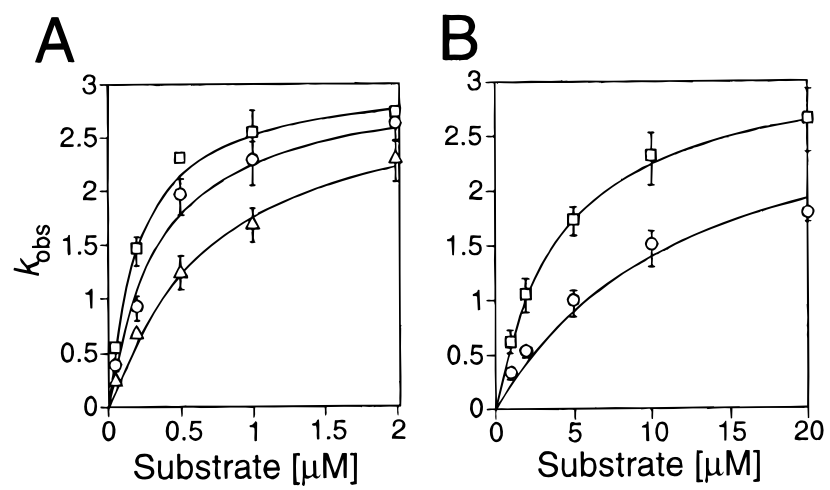

FIGURE 4: Inhibition of ligase by product. (A) Product inhibition in the $207 \mathrm{t}$ reaction. Ribozyme $(25 \mathrm{nM})$ was incubated at $\mathrm{pH} 6.0$ with $\mathrm{S}^{\mathrm{OH}}(4 \mu \mathrm{M})$ and the indicated concentration of ${ }^{\text {PPP }}$ S. Rates shown are those with no added product $(\square), 150 \mathrm{nM}$ product $(\bigcirc)$, and $600 \mathrm{nM}$ product $(\triangle)$. The line through the points measured with no added product is the best fit to the Michaelis-Menten equation, and indicates a $k_{\text {cat }}$ of $3 \mathrm{~min}^{-1}$ and a $K_{\mathrm{m}}$ of $220 \mathrm{nM}$. The other lines show the rates expected with these Michaelis-Menten values and a $K_{\mathrm{i}}$ of $230 \mathrm{nM}$ (eq 4). Error bars indicate the standard deviation of $\geq 2$ independent measurements ( $\geq 4$ for uninhibited data set). (B) Product inhibition in the 210 t reaction. Ribozyme $(25 \mathrm{nM})$ was incubated at $\mathrm{pH} 6.0$ with $\mathrm{S}^{\mathrm{OH}}(25 \mu \mathrm{M})$ and the indicated concentration of PPPS. Rates shown are those with no added product $(\square)$ and $15 \mu \mathrm{M}$ product $(O)$. The line through the points measured with no added product is the best fit to the Michaelis-Menten equation, and indicates a $k_{\text {cat }}$ of $3 \mathrm{~min}^{-1}$ and a $K_{\mathrm{m}}$ of $4.2 \mu \mathrm{M}$. The other line is the best fit to eq 4 using this $k_{\text {cat }}$ and $K_{\mathrm{m}}$, and indicates a $K_{\mathrm{i}}$ of $12.8 \mu \mathrm{M}$. Competitive behavior was confirmed for $207 \mathrm{t}$. Error bars indicate the standard deviation of $\geq 3$ independent measurements.

Scheme 1

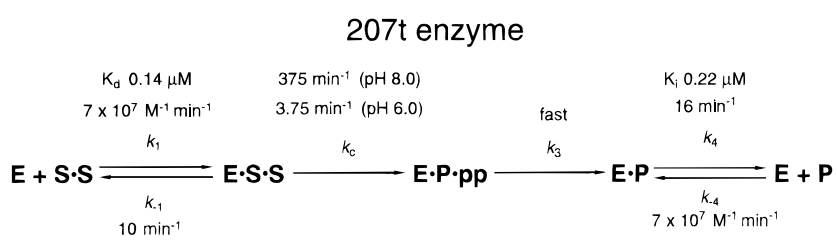

and 8.0. This modeling built on the notion that $k_{\mathrm{c}}$ is rate limiting at low $\mathrm{pH}$ and that the product-dissociation rate becomes limiting at higher $\mathrm{pH}$. It initially assumed that $\mathrm{pH}$ changes from 6.0 to 8.0 did not significantly change the association or dissociation rate constants of substrates or products. Subsequent experiments confirmed the validity of this assumption. The elemental rate constants determined by this modeling and refined in subsequent experiments are shown (Scheme 1).

Pyrophosphate Binding and Pyrophosphorolysis. The reverse of ligation (cleavage with $\mathrm{PP}_{\mathrm{i}}$, forming a triphosphate) has been detected using the primer-extension format (3), where the cleaved product can dissociate before religating (M. Glasner, C. Yen, E. Ekland, D.P.B., manuscript in preparation). This pyrophosphorolysis reaction is very inefficient $\left(k_{\text {cat }} / K_{\mathrm{m}}{ }^{\mathrm{PP}_{\mathrm{i}}}=0.013 \mathrm{M}^{-1} \mathrm{~min}^{-1}\right)$. It is not saturable by soluble amounts of $\mathrm{PP}_{\mathrm{i}}$, indicating that the $K_{\mathrm{m}}{ }^{\mathrm{PP}_{\mathrm{i}}}$ exceeds 1 $\mathrm{mM}$. Assuming that the rate constant for pyrophosphate association $\left(k_{-3}\right)$ is comparable to association constants of other small-molecule enzyme interactions $\left(10^{8}-10^{10} \mathrm{M}^{-1}\right.$ $\min ^{-1}$; ref 29) and that $K_{\mathrm{m}} \mathrm{PP}_{\mathrm{i}}=K_{\mathrm{d}}{ }^{\mathrm{PP}_{\mathrm{i}}}$, then the lower limit on the $K_{\mathrm{m}}{ }^{\mathrm{PP}_{\mathrm{i}}}$ can be used to calculate a lower limit for rate constant for pyrophosphate release $\left(k_{3}\right)$ of $10^{5} \mathrm{~min}^{-1}\left(10^{8}\right.$ $\mathrm{M}^{-1} \min ^{-1} \times 1 \mathrm{mM}$ ). Thus, $k_{3}$ is denoted as "fast" in our 
kinetic scheme. The inability to saturate $\mathrm{PP}_{\mathrm{i}}$ binding precluded determination of the rate constant for the reverse of the chemical step $\left(k_{-2}\right)$, although inefficiency of the reverse reaction allows pyrophosphorolysis to be neglected when determining the remaining elemental rate constants.

Rate Constants for Dissociation $\left(k_{4}\right)$ and Association of Product $\left(k_{-4}\right)$. Although the measured $k_{\text {cat }}$ for the $207 \mathrm{t}$ ribozyme at $\mathrm{pH} 8.0$ was only $16 \mathrm{~min}^{-1}$, the rates measured for the $210 \mathrm{t}$ ribozyme suggested that the chemical step $\left(k_{\mathrm{c}}\right)$ for these ligases was much faster, exceeding the $k_{\mathrm{cat}(\mathrm{pH} \text { 8.0) }}$ of $210 \mathrm{t}\left(140 \mathrm{~min}^{-1}\right.$; Table 1$)$. With this model, product release was by far the limiting step under these conditions, so $k_{4}$ closely approaches the $k_{\text {cat }}\left(16 \mathrm{~min}^{-1}\right)$. Because the observed product inhibition was competitive, it follows that $K_{\mathrm{i}}=K_{\mathrm{d}}$, and thus $k_{4} / K_{\mathrm{i}}=$ rate constant for product association $\left(k_{-4}\right)$ $=7 \times 10^{7} \mathrm{M}^{-1} \mathrm{~min}^{-1}$.

Rate Constant for the Chemical Step $\left(k_{\mathrm{c}}\right)$. The rate constant for product release is assumed to be constant throughout the $\mathrm{pH}$ range $6.0-8.0$, so the $k_{4}$ of $16 \mathrm{~min}^{-1}$ was used in the formula $k_{\mathrm{cat}(\mathrm{pH} 6.0)}=\left(k_{\mathrm{c}(\mathrm{pH} 6.0)} \times k_{4}\right) /\left(k_{\mathrm{c}(\mathrm{pH} 6.0)}+k_{4}\right)$ to calculate the rate constant for the chemical step at pH $6.0\left(3.75 \mathrm{~min}^{-1}\right)$. Because the rate of chemistry is log-linear with $\mathrm{pH}$ in this range, the $k_{\mathrm{c}(\mathrm{pH} 8.0)}$ can be extrapolated to $375 \mathrm{~min}^{-1}$. The extrapolation is reasonable because catalysis at a rate of 360 $\mathrm{min}^{-1}$ can be observed directly for the $210 \mathrm{t}$ ribozyme at $\mathrm{pH}$ 9.0 (Table 1), and thus there are not likely to be intervening conformational steps to consider.

Rate Constant for Substrate Association ( $\left.k_{1}\right)$ and an Initial Estimate of the Rate Constant for Substrate Dissociation $\left(k_{-1}\right)$. Under conditions where [S] is well below the $K_{\mathrm{m}}$ and the chemical step is both essentially irreversible and much faster than substrate dissociation, $k_{\text {cat }} / K_{\mathrm{m}}$ is equal to the rate constant for substrate association. These conditions hold for $207 \mathrm{t}$ at $\mathrm{pH}$ 8.0. The rate constant for substrate association $\left(k_{1}\right)$ is thus given by $k_{\mathrm{cat}(\mathrm{pH} 8.0)} / K_{\mathrm{m}(\mathrm{pH} 8.0)}=7 \times 10^{7} \mathrm{M}^{-1} \mathrm{~min}^{-1}$. The rate constant for substrate dissociation $\left(k_{-1}\right)$ can be calculated by eq 16 (29), assuming kinetic Scheme 1, and

$$
k_{-1}=\mathrm{K}_{\mathrm{m}} \frac{\left[k_{1}\left(k_{\mathrm{c}}+k_{4}\right)\right]}{k_{4}}-k_{\mathrm{c}}
$$

yields an initial estimate of $15 \mathrm{~min}^{-1}$.

Measurement of Substrate Dissociation Rate Constant $\left(k_{-1}\right)$ and the Ribozyme-Specific Activity. To refine the initial estimate of $k_{-1}$, we measured this rate constant with an experiment in which a trace amount of radiolabeled substrateenzyme complex was subjected to a $\mathrm{pH}$ jump in the presence of a large excess of unlabeled substrate. This also allowed us to test our initial assumption regarding the $\mathrm{pH}$ independence of substrate binding between $\mathrm{pH}$ 6.0-8.0. Such a test was important because interactions involving the ${ }^{\mathrm{PPP}} \mathrm{S}$ $\gamma$-phosphate $\left(\mathrm{p} K_{\mathrm{a}}=6.8\right)$ might have made substrate dissociation $\mathrm{pH}$-sensitive over this range.

With the $\mathrm{pH}$ jump, a burst of product was observed, reflecting the amount of product formed as the preformed $\mathrm{E} \cdot \mathrm{S}$ complexes partitioned into either $\mathrm{E} \cdot \mathrm{P}$ (at a rate equaling $k_{\mathrm{c}}$ ) or $\mathrm{E}+\mathrm{S}$ (at a rate equaling $k_{-1}$ ). Further radiolabeled product formation was much slower because the presence of the unlabeled substrate chase prevented most of the enzyme from binding free labeled substrate. The magnitude of the initial burst corresponds to the ratio of the rates at which the two outcomes occur $\left(k_{\mathrm{d}} / k_{-1}\right)$. By changing the $\mathrm{pH}$ (from 6.0 to 8.0), this ratio was measured at five different $k_{\mathrm{c}}$ 's, allowing measurement of substrate dissociation under a wide range of catalytic efficiency (Figure 5).

The results of the partitioning experiments were compared to those predicted using the chemical kinetics simulation program KINSIM (10). We observed that the data did not match the simplest model, which assumed that all of the ribozyme was in an active conformation (Figure 5, dashed lines). Instead, they fit well to a more complicated scheme in which $30 \%$ of the ribozyme was inactive yet could still bind substrate (Figure 5, solid lines). The two models are best distinguished at high $\mathrm{pH}$, where the actual burst height was only $70 \%$ of that predicted by the simplest model.

Examination of the control reaction, which had a pH jump but not a chase of unlabeled substrate, further supported the conclusion that only $70 \%$ of the enzyme existed in an active conformation. If all of the ribozymes were in an active conformation and the catalytic step was significantly faster than the rate of substrate dissociation, all of the substrate would be converted to product very quickly (within the first second). If, however, a significant fraction of inactive enzyme existed, then there would be a corresponding fraction of substrate that was not converted to product as quickly, reflecting either the time necessary for the substrate complex to dissociate from an inactive enzyme and bind an active molecule or the time for an inactive $\mathrm{E} \cdot \mathrm{S}$ complex to convert to an active conformation. The results showed that although most of the substrate reacted very quickly $(<1 \mathrm{~s})$, a small but significant fraction needed more time to react (Figure 5, $\mathrm{pHs}$ 7.0, 7.5, and 8.0). These data are inconsistent with a model in which the ribozymes were uniformly active (Figure 5 , dotted line) and better match a model in which $30 \%$ of the ribozymes existed in an alternate, inactive conformation (Figure 5, solid line).

Using the refined model in which $70 \%$ of the ribozymes are in an active conformation, we found that the rate of substrate dissociation $\left(k_{-1}\right)$ was $10 \mathrm{~min}^{-1}$ throughout the $\mathrm{pH}$ range tested. This supported our earlier assumption that binding of substrate (and product) was not significantly affected by $\mathrm{pH}$ changes within the range of $\mathrm{pH} 6-8$. Using $k_{-1}=10 \mathrm{~min}^{-1}$ and $k_{1}=7 \times 10^{7} \mathrm{M}^{-1} \mathrm{~min}^{-1}$, the calculated $K_{\mathrm{d}}$ of the $\mathrm{E} \cdot \mathrm{S}$ complex is $0.14 \mu \mathrm{M}$.

It should be noted that our favored model assumes that a ribozyme in an inactive conformation is essentially unable to promote ligation, yet binds substrate with the same affinity as does a ribozyme in the active conformation. It also assumes that the equilibrium between inactive and active conformations is unperturbed by binding of substrate or product. We propose that this is the simplest explanation for the data observed in the $\mathrm{pH}$ jump-partitioning experiments, as they are difficult to explain in any other way without invoking a complex relationship between $\mathrm{pH}$ and substrate affinity.

The presence of an inactive enzyme fraction made necessary the minor adjustment of the other individual rate constants. For clarity, all rate constants reported in this study have been corrected for this lowered ribozyme specific activity. 

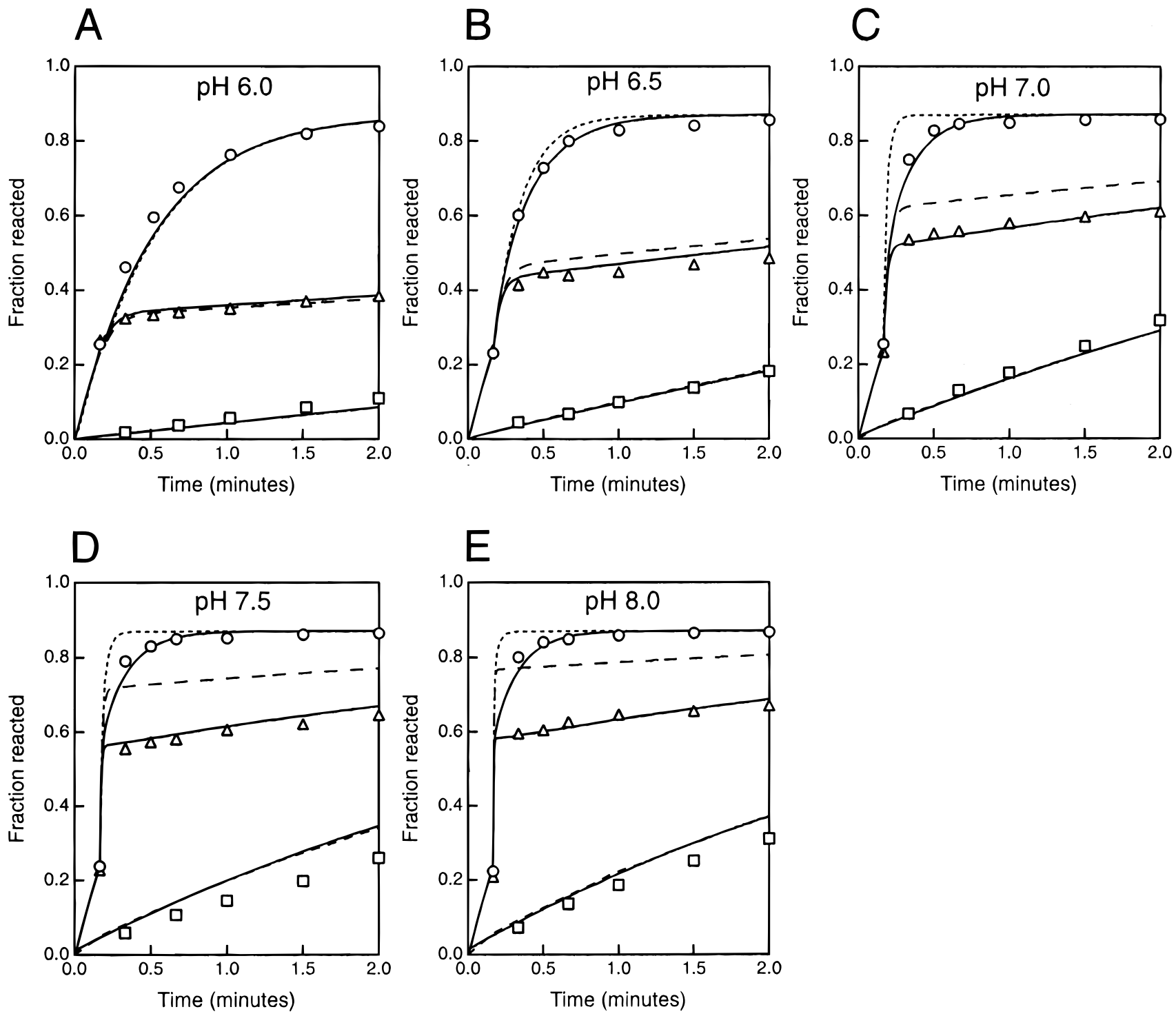

FIGURE 5: Measurement of substrate dissociation rate constants and enzyme specific activity by pH-jump partitioning experiments. Each panel shows three separate time courses. The $\mathrm{pH}$-jump partitioning experiments $(\Delta)$ were performed as follows: Ribozyme $(1 \mu \mathrm{M})$ and labeled $\mathrm{S}^{\mathrm{OH}} \cdot \mathrm{PPP} S$ complex were mixed in reaction buffer at $\mathrm{pH}$ 6.0. After $10 \mathrm{~s}$, the reaction was mixed with an equal volume of a solution that increased the $\mathrm{pH}$ to the desired value $(6.0-8.0)$ and added unlabeled $\mathrm{S}^{\mathrm{OH} \cdot \mathrm{PPP}} \mathrm{S}$ complex to a final concentration of $20 \mu \mathrm{M}$. Control experiments with no substrate chase $(O)$ were performed in the same way, except that the chase solution raised the $\mathrm{pH}$ without adding any unlabeled $S^{\mathrm{OH} \cdot \mathrm{PPP}} \mathrm{S}$ complex. For the control experiment with no pulse of labeled substrate $(\square)$, the unlabeled $S^{\mathrm{OH} \cdot \mathrm{PPP}} \mathrm{S}$ complex was mixed with the labeled $S^{\mathrm{OH} \cdot P P P} S$ complex before starting the reaction. The solid lines through each set of points show the expected accumulation of product in an experiment simulated using the rate constants shown in Scheme $1\left(k_{-1}=10 \mathrm{~min}^{-1}\right)$ and assuming that $87 \%$ of $\mathrm{S}$ is active and $70 \%$ of $\mathrm{E}$ is active. The dashed line in each panel represents a partitioning experiment simulated assuming $87 \%$ active $\mathrm{S}$ and $100 \%$ active $\mathrm{E}$, where rate constants were adjusted from those in Scheme 1 to account for additional active $\mathrm{E}\left(k_{1}=4.7 \times 10^{7} \mathrm{M}^{-1} \mathrm{~min}^{-1}, k_{-1}\right.$ $=10 \mathrm{~min}^{-1}, k_{2}=2.3 \mathrm{~min}^{-1}$ at $\mathrm{pH} 6.0, k_{2}=230 \mathrm{~min}^{-1}$ at $\mathrm{pH} 8.0, k_{-2}=0, k_{4}=11 \mathrm{~min}^{-1}$, and $k_{-4}=4.7 \times 10^{7} \mathrm{M}^{-1} \mathrm{~min}^{-1}$ ). The dotted line in each panel represents a experiment simulated without a substrate chase, assuming $87 \%$ active S, $100 \%$ active E, and using the same adjusted rate constants as for the dashed line.

\section{DISCUSSION}

The 207t kinetic framework (Scheme 1) suggests the following view of ligation (at $\mathrm{pH}$ 8.0). The ribozyme molecules fold into either active or inactive conformations upon addition of buffer, salts, and $\mathrm{S}^{\mathrm{OH}}$. Although there are as yet no measurements of the rate of this folding for the multiple-turnover constructs, we suggest that it takes place quickly $(<1 \mathrm{~s})$ because there is no observed lag in product formation during self-ligation, even with time points as early as $5 \mathrm{~s}$ (Figure 2). The majority of the ribozyme molecules quickly finds an active conformation and reacts in a rapid burst with a $k_{\mathrm{c}}$ of approximately $375 \mathrm{~min}^{-1}$. After ligation, product is released at a rate of $16 \mathrm{~min}^{-1}$. This final step appears to be the major obstacle to improving the overall catalytic rate of $207 \mathrm{t}$. Product release limiting the overall catalytic rate has been observed in other ribozymes and might be expected given that most known ribozymes (derived both naturally and artificially) were evolved to perform precise single-turnover reactions.

The 210t ribozyme, which differs from its parent $(207 \mathrm{t})$ by the rearrangement of three base pairs, catalyzes the same reaction with a much higher $k_{\mathrm{cat}(\mathrm{pH}}$ 8.0) $\left(140 \mathrm{~min}^{-1}\right.$ vs 16 $\left.\min ^{-1}\right)$. We can model a similar framework for the $210 \mathrm{t}$ reaction (Scheme 2) in order to more completely describe this ribozyme's activity and the differences from its parent. Michaelis-Menten parameters and product $K_{\mathrm{i}} \mathrm{s}$ were mea- 
Scheme 2

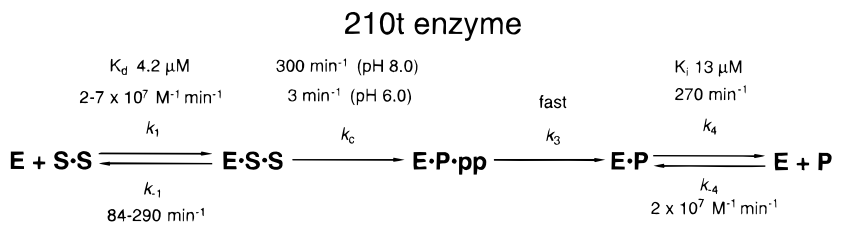

sured as with 207t (Table 1), and the reaction was modeled as follows, using the insights from the $207 \mathrm{t}$ reaction.

Rate Constant for the Chemical Step $\left(k_{\mathrm{c}}\right)$. The $210 \mathrm{t} k_{\mathrm{cat}}$ at $\mathrm{pH} 8.0\left(140 \mathrm{~min}^{-1}\right)$ suggested a very fast rate of product release, so $k_{\mathrm{c}}$ at $\mathrm{pH} 6.0$ must be very close to the $k_{\text {cat }}(3$ $\min ^{-1}$ ). This value for $k_{\mathrm{c}}$ agreed well with the corresponding rate constant from the $207 \mathrm{t}$ reaction. As discussed earlier, the changes made between the two ribozymes did not significantly affect the chemical step.

Rate Constants for Dissociation $\left(k_{4}\right)$ and Association of Product $\left(k_{-4}\right)$. Using the measured $k_{\text {cat }}$ and calculated $k_{\mathrm{c}}$ for the $210 \mathrm{t}$ reaction at $\mathrm{pH} 8.0$, the rate constant for product dissociation $\left(k_{4}\right)$ was estimated to be $270 \mathrm{~min}^{-1}\left[k_{\mathrm{cat}(\mathrm{pH} 8.0)}=\right.$ $\left.\left(k_{\mathrm{c}(\mathrm{pH} 8.0)} \times k_{4}\right) /\left(k_{\mathrm{c}(\mathrm{pH} 8.0)}+k_{4}\right)\right]$. The rate constant for product association $\left(k_{-4}\right)$ can be estimated as $k_{4} / K_{\mathrm{i}}=2 \times 10^{7} \mathrm{M}^{-1}$ $\mathrm{min}^{-1}$. It is difficult to say whether the 3 -fold difference between $k_{-4}$ values of the two enzymes is significant. Dayto-day variation was generally less than $\pm 20 \%$ for any two experiments performed with the same reagents, but as much as 2-fold when performed with different preparations of reagents.

Rate Constant for Substrate Association ( $\left.k_{1}\right)$ and an Initial Estimate of the Rate Constant for Substrate Dissociation $\left(k_{-1}\right)$. In contrast with the parent ribozyme, where $k_{1}$ was simply $k_{\text {cat }} / K_{\mathrm{m}}$, we do not have an accurate measure of $k_{1}$ for $210 \mathrm{t}$. If the $k_{1}$ for $210 \mathrm{t}$ matched the $k_{1}$ for $207 \mathrm{t}$, it would be approximately $7 \times 10^{7} \mathrm{M}^{-1} \mathrm{~min}^{-1}$. On the other hand, for the parent ribozyme, $k_{1}$ equaled $k_{-4}$; if the same was true for 210 t, then its $k_{1}$ may be closer to $2 \times 10^{7} \mathrm{M}^{-1} \mathrm{~min}^{-1}$. The range for $k_{1}$ shown in Scheme 2 reflects these two possibilities.

The low affinity of the 210t ribozyme for its substrate also hampered measurements of the substrate dissociation rate constant. The partitioning approach used for $207 \mathrm{t}$ was not applicable here; the high $K_{\mathrm{m}}$ for the 210t ligase would have required both high enzyme concentrations to saturate the substrate pulse and unattainable substrate levels for an effective chase. Approaches using dilution rather than an unlabeled chase to partition the labeled $\mathrm{E} \cdot \mathrm{S}$ complex were likewise beyond the scope of these studies because they would have required near-instantaneous (millisecond) mixing. The rate constant for substrate dissociation was therefore estimated as $\left(K_{\mathrm{d}}\right)\left(k_{1}\right)=85-290 \mathrm{~min}^{-1}$, where $K_{\mathrm{d}}$ was estimated from $K_{\mathrm{m}}$ at $\mathrm{pH} 6$.

Although the two ribozyme reactions presented here are alike in most respects, the multiple-turnover rates of the $210 \mathrm{t}$ ribozyme place it in a unique position with regard to RNA catalysis. The RNA component of RNase P and a multipleturnover derivative of the Tetrahymena self-splicing intron are also capable of achieving fast $k_{\mathrm{c}} \mathrm{s}\left(>100 \mathrm{~min}^{-1}\right)$, but like $207 \mathrm{t}$, they are usually held to relatively low turnover rates by their slow product release $(11,14)$. To circumvent this limitation, product-binding mutants can be used, but these mutants typically have lowered affinity for the sub- strate, necessitating high substrate concentration to observe the high multiple-turnover rate. Therefore, this strategy is expected to falter at the point that the binding mutants begin to affect $k_{\mathrm{c}}$ or the high concentration of RNA substrate begins to inhibit the ribozyme. At low $\mathrm{Mg}^{2+}$ concentration, RNase P RNA has a $k_{\text {cat }}$ of $37 \mathrm{~min}^{-1}(30,31)$ and should be able to exceed $100 \mathrm{~min}^{-1}$ with lowered $\mathrm{NH}_{4}{ }^{+}$concentration (J. Kurz and C. Fierke, personal communication). The 210t ribozyme's ability to catalyze its reaction with $k_{\text {cat }(\mathrm{pH} 9)}=360$ $\min ^{-1}$ shows that ribozymes can perform multiple-turnover reactions on RNA substrates without severe limitation by product release. Two factors contribute to the fast catalytic turnover of the $210 \mathrm{t}$ ribozyme at $\mathrm{pH} 9$. First, the $k_{\mathrm{c}}$ is very fast, probably exceeding $1000 \mathrm{~min}^{-1}$. Second, the ribozyme binds its substrate at least as tightly as it binds its product. The 210t appears to bind substrate slightly (3-fold) more tightly than it binds product (compare substrate $K_{\mathrm{d}}$ and product $K_{\mathrm{i}}$ in Scheme 2), allowing high multiple-turnover rates to be observed at somewhat lower substrate concentrations. This possible preference for binding substrate would be unusual for RNA-catalyzed ligation; if it could be enhanced, more rapid rates could be achieved.

The catalytic efficiency of the class I ligase $\left[k_{\mathrm{cat}(\mathrm{pH}} 8.0\right) /$ $\left.K_{\mathrm{m}}\right]$ approaches the substrate-enzyme association rate. This is a feature typical of ribozymes that bind their substrate by forming a Watson-Crick helix $(11,13,32,33)$ and can be thought to satisfy the criteria for "catalytic perfection" (11), although the ribozyme catalytic efficiencies are considerably less than those of classical diffusion-controlled enzymes. For the class I ligase, the P2 helix must form during binding of the substrate complex. The substrate-enzyme association rate constant is within the range observed for the association rate constants of model RNA helices (range: $10^{7}-10^{9} \mathrm{M}^{-1}$ $\mathrm{min}^{-1}$; refs 34-36). It is reasonable to propose that formation of P2 limits the substrate association rate constant, and thus attempts to improve the catalytic efficiency $\left(k_{\mathrm{cat}} / K_{\mathrm{m}}\right)$ of the class I ligase would focus on increasing the rate constant for P2 formation. Perhaps additional contacts to the backbone of the ribozyme arm of P2 could increase the association rate constant by presenting the arm more favorably for helix nucleation.

Comparison of the 210t $\left.k_{\mathrm{cat}(\mathrm{pH}} 8\right)\left(140 \mathrm{~min}^{-1}\right)$ with the uncatalyzed reaction in the equivalent buffer, salt, and temperature $\left[k_{\text {uncat }}(\mathrm{pH} 8.0)=1.2 \times 10^{-7} \mathrm{~min}^{-1}\right.$; ref 2] indicates a rate enhancement of $1.2 \times 10^{9}$. This refinement of our previously reported value $\left(8 \times 10^{8}\right.$; ref 2$)$ reflects the correction for ribozyme specific activity. The rate enhancement can also be expressed in terms of $k_{\mathrm{c}}$. The enhancement of $k_{\mathrm{c}(\mathrm{pH}}{ }_{8)}\left(375 \mathrm{~min}^{-1}\right)$ over $k_{\text {uncat }(\mathrm{pH}}$ 8.0) is $3 \times 10^{9}$. The Tetrahymena group I intron and RNase P RNA also have fast chemical steps, yet they promote somewhat more difficult uncatalyzed reactions, and so the $k_{\mathrm{c}}$ for derivatives of these ribozymes are $10^{11}-10^{13}$ times faster than $k_{\text {uncat }}(11$, $30,31,37)$.

The most interesting optimization of the class I ligase would be an increase in the rate of chemistry. At $22{ }^{\circ} \mathrm{C}$ and physiological $\mathrm{pH}$, the $k_{\mathrm{c}}$ of the class I ligase and $k_{\mathrm{c}} \mathrm{S}$ of the ribozymes with the fastest known chemical steps (Tetrahymena group I intron and RNase P RNA) are all about the same $\left(100 \mathrm{~min}^{-1}\right)$. Although natural ribozymes are not necessarily optimized for speed, it is noteworthy that the ligase has attained a comparable $k_{\mathrm{c}}$ without the benefit of 
billions of years of evolution. Indeed, it is curious that our prototype ribozyme (construct b1-207) has a fast $k_{\mathrm{c}}$; it was generated by combining the features of ribozyme variants selected under conditions (a 30-s incubation at $\mathrm{pH} 7.4$ ) that would not have stringently rewarded quick chemistry (6). With the finding that lowering $\mathrm{pH}$ can isolate $k_{\mathrm{c}}$, it should be feasible, using rapid-quench techniques, to select for variants with faster rates of chemistry. Such an approach would more directly explore, and perhaps extend, the limits of the class I ribozyme as well as those of RNA catalysis in general.

\section{ACKNOWLEDGMENT}

We thank Carol Fierke and Timothy McConnell for helpful discussions and comments on the manuscript. We also thank Carl Frieden and Chuck Merryman for assistance with the simulation software, and Phil Zamore, Mike Lawrence, and other members of the lab for helpful comments on this manuscript.

\section{REFERENCES}

1. Bartel, D. P., and Szostak, J. W. (1993) Science 261, 14111418.

2. Ekland, E. H., Szostak, J. W., and Bartel, D. P. (1995) Science 269, 364-370

3. Ekland, E. H., and Bartel, D. P. (1996) Nature 382, 373376.

4. Bartel, D. P. (1999) in The RNA World II (Gesteland, R. F., Cech, T. R., and Atkins, J. F., Eds.) pp 143-162, Cold Spring Harbor Laboratory Press, Plainview, NY.

5. Wright, M. C., and Joyce, G. F. (1997) Science 276, 614617.

6. Ekland, E. H., and Bartel, D. P. (1995) Nucleic Acids Res. 23, 3231-3238.

7. Tuschl, T., Sharp, P. A., and Bartel, D. P. (1998) EMBO J. 17, 2637-2650.

8. Milligan, J. F., Groebe, D. R., Witherell, G. W., and Uhlenbeck, O. C. (1987) Nucleic Acids Res. 15, 8783-8798.

9. Dawson, R. M., Elliott, D. C., Elliott, W. H., and Jones, K. M. (1986) Data For Biochemical Research, 3rd ed., Oxford University Press, Oxford.

10. Barshop, B. A., Wrenn, R. F., and Frieden, C. (1983) Anal. Biochem. 120, 134-145.

11. Herschlag, D., and Cech, T. R. (1990) Biochemistry 29, 10159-10171.

12. Collins, R. A., and Olive, J. E. (1993) Biochemistry 32, 27952799.

13. Hertel, K. J., Herschlag, D., and Uhlenbeck, O. C. (1994) Biochemistry 33, 3374-3385.
14. Beebe, J. A., and Fierke, C. A. (1994) Biochemistry 33, 10294-10304.

15. Mei, R., and Herschlag, D. (1996) Biochemistry 35, 57965809.

16. Walter, N. G., and Burke, J. M. (1997) RNA 3, 392-404.

17. Dahm, S. C., Derrick, W. B., and Uhlenbeck, O. C. (1993) Biochemistry 32, 13040-13045.

18. Smith, D., and Pace, N. R. (1993) Biochemistry 32, 52735281.

19. Weeks, K. M., and Cech, T. R. (1995) Biochemistry 34, 77287738.

20. Nesbitt, S., Hegg, L. A., and Fedor, M. J. (1997) Chem. Biol. 4, 619-630.

21. Mizrahi, V., Henrie, R. N., Marlier, J. F., Johnson, K. A., and Benkovic, S. J. (1985) Biochemistry 24, 4010-4018.

22. Herschlag, D., Piccirilli, J. A., and Cech, T. R. (1991) Biochemistry 30, 4844-4854.

23. Xia, T., Santa Lucia, J., Jr., Burkard, M. E., Kierzek, R., Schroeder, S. J., Jiao, X., Cox, C., and Turner, D. H. (1998) Biochemistry 37, 14719-14735.

24. Legault, P., and Pardi, A. (1997) J. Am. Chem. Soc. 119, 6621-6628.

25. Saenger, W. (1984) Principles of Nucleic Acid Structure, Springer-Verlag, New York.

26. Knitt, D. S., and Herschlag, D. (1996) Biochemistry 35, 15601570 .

27. Hickey, T. D., and Turner, D. H. (1985) Biochemistry 24, 3987-3991.

28. Narlikar, G. J., Gopalakrishnan, V., McConnell, T. S., Usman, N., and Herschlag, D. (1995) Proc. Natl. Acad. Sci. U.S.A. 92, 3668-3672.

29. Fersht, A. (1985) Enzyme Structure and Mechanism, 2nd ed., W. H. Freeman, New York.

30. Beebe, J. A., Kurz, J. C., and Fierke, C. A. (1996) Biochemistry 35, 10493-10505.

31. Harris, M. E., Nolan, J. M., Malhotra, A., Brown, J. W., Harvey, S. C., and Pace, N. R. (1994) EMBO J. 13, 39533963.

32. Esteban, J. A., Banerjee, A. R., and Burke, J. M. (1997) J. Biol. Chem. 272, 13629-13639.

33. Santoro, S. W., and Joyce, G. F. (1997) Proc. Natl. Acad. Sci. U.S.A. 94, 4262-4266.

34. Nelson, J. W., and Ignacio Tinoco, J. (1982) Biochemistry 21, 5289-5295.

35. Porschke, D., and Eigen, M. (1971) J. Mol. Biol. 62, $361-$ 381.

36. Craig, M. E., Crothers, D. M., and Doty, P. (1971) J. Mol. Biol. 62, 383-401.

37. Tsang, J., and Joyce, G. F. (1996) J. Mol. Biol. 262, 31-42. BI992654U 